\title{
Oxysterols Receptor LXR-Alpha
}

National Cancer Institute

\section{Source}

National Cancer Institute. Oxysterols Receptor LXR-Alpha. NCI Thesaurus. Code C132115.

Oxysterols receptor LXR-alpha (447 aa, $50 \mathrm{kDa}$ ) is encoded by the human NR1H3 gene. This protein is involved in transcriptional regulation and cholesterol homeostasis. 